Abstracted/indexed in Academic Search Complete, Asia Journals Online, Bangladesh Journals Online, Biological Abstracts, BIOSIS Previews, CAB Abstracts, Current Abstracts, Directory of Open Access Journals, EMBASE/Excerpta Medica, Global Health, Google Scholar, HINARI (WHO), International

Pharmaceutical Abstracts, Open J-gate, Science Citation Index Expanded, SCOPUS and Social Sciences Citation Index;

ISSN: $1991-0088$

\title{
Organochlorine insecticides (DDT and heptachlor) in dry fish: Traditional washing and cooking effect on dietary intake
}

\author{
Md. Nurul Huda Bhuiyan', Habibur Rahman Bhuiyan', Kabir Ahmed', Mamtaz Dawlat- \\ ana $^{2}$, K. M. Formuzul Haque ${ }^{2}$, Matiur Rahim² and Md. Nazrul Islam Bhuiyan'
}

${ }^{1}$ BCSIR Laboratories Chittagong, Chittagong 4220, Bangladesh; ${ }^{2}$ Institute of Food Science Technology, BCSIR, Dhaka, Bangladesh.

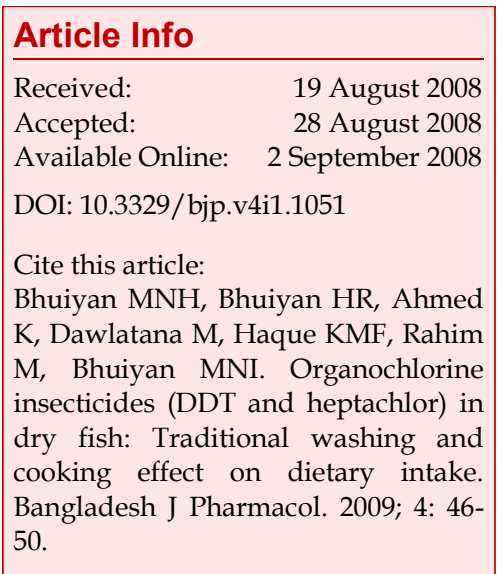

\section{Abstract}

The concentrations of organochlorine insecticides (DDT and heptachlor) were investigated to estimate the effect of various washing and boiling/cooking to elucidate the concentration level we intake actually. For this study five most popular dry fish samples namely bombay duck (loittya), ribbon fish (chhuri), shrimp (chingri), chinese pomfret (rupchanda) and Indian salmon (lakhua) were analyzed. The highest concentrations of DDT and heptachlor were found $737.2 \mathrm{ppb}$ (Indian salmon, normal) and $44.8 \mathrm{ppb}$ (shrimp, normal) respectively; after boiling treatment a big amount was washed out and remained only 135.5 and $16.9 \mathrm{ppb}$ respectively. Boiling treatment was found more effective than the others.

\section{Introduction}

For long conservation of fish by drying is common practice in Bangladesh. This practice is usually made in the remote coastal isolated islands and in inland depressions where chilling and freezing facilities are lacking. The finally dried fish products are generally stored in a dump warehouse nearby coastal towns. In addition to this, the weather is humid particularly during the monsoon period and the dry fishes absorbed moisture rapidly that the fish becomes suitable for infestation by beetles and mites. Most unexpected causes of infestation are that the fishermen do not dry fishes properly due to loss of weight i.e., the fishermen want more profit selling the dry fishes in weight. For protection of dry fish from infestation they use a mixture of organochlorine (DDT and heptachlor) insecticides (Bhuiyan et al., 2008). Some analyses in Bangladesh show alarming pollutants in fish like DDT and heptachlor (BCAS, 1990). In Kuakata (a fish processing zone in Bangladesh), high level of DDT powder (locally known as white powder) is used though Bangladesh banned the 'dirty dozen' in 1997 (Barua, 2007) and there is no statistical figure about these organochlorine insecticides in Bangladesh (UNEP, 2002).

DDT is highly stable under most environmental conditions and very lipophilic (Kow: $9.6 \times 105$ ), which favors its bioaccumulation throughout the food chain (Morrison and Newell, 1999). DDT can transfer from generation to generation through breast milk (Solomon and Weiss, 2001). In areas where it is used for malaria control, infants can be exposed via breast milk (Bouwman et al., 2006; Ntow et al., 2008). It is classified as "moderately toxic" by the US National Toxicological Program and "moderately hazardous" by WHO and a B2 probable human carcinogen (WHO, 2005). Exposed to DDT increased the incidence of non-allergic asthma (Brown, 2007), linked to diabetes (Jones et al., 2008), an elevated risk of cancers of the liver and biliary tract (Rogan and Chen, 2005) and the risk of breast cancer (Clapp et al., 2008). On the other hand, heptachlor is a probable human carcinogen (B2) and can pass directly 
from a mother's blood to an unborn baby through the placenta, it also related to liver tumors (LDWG, 2007).

The objectives of this study were to detection and determination of the concentration level of insecticides (DDT and heptachlor) in dry fish at normal (without washing) and after various traditional washing to elucidate the actual concentration level of insecticides we intake through dry fish.

\section{Materials and Methods}

\section{Sampling}

Five most popular dry fish samples namely bombay duck (loittya), ribbon fish (chhuri), shrimp (chingri), Chinese pomfret (rupchanda) and Indian salmon (lakhua) were collected from Asadgonj (whole sell market of dry fish) of Chittagong, Bangladesh in July 2008. Total number of samples were 20 .

The control samples of five different fishes were collected from drying yards of Sonadia island (a fish processing zone of Bangladesh) that are known sample treated with no insecticides and taken into account as blank.

\section{Apparatus}

Mincer fish chopper (Weisser No. $81 \mathrm{~K}$ ), soxhlet extractor, chromatographic tube $(20 \mathrm{~mm}$ i.d. $50 \mathrm{~cm}$ long), sample concentrator (Techne dry block DB.3) and gas chromatograph (GC-14B, Shimadzu).

\section{Reagents}

Acetone, diethyl ether, dimethyl formamide saturated with petroleum ether, n-hexane, petroleum ether (30$\left.60^{\circ} \mathrm{C}\right)$, petroleum ether $\left(30-60^{\circ} \mathrm{C}\right)$ saturated with dimethyl formamide, eluting mixture I (petroleum ether + diethyl ether 94:6 v/v), standard solutions, eosin solution ( $2 \mathrm{mg}$ in $100 \mathrm{~mL}$ ), sodium sulfate solution ( $2 \mathrm{~g} / 100 \mathrm{~mL} \mathrm{NaSO}_{4} 10 \mathrm{H}_{2} \mathrm{O}$ ), sodium sulfate anhydrous (heated for at least 2 hours at $550^{\circ} \mathrm{C}$ ), florisil $60-100$ mesh (heated for at least 2 hours at $550^{\circ} \mathrm{C}$, cold and stored in tightly stoppered container, prior to use heated for at least 5 hours at $130^{\circ} \mathrm{C}$, cold and add $5 \%$ $\mathrm{w} / \mathrm{w}$ water, shake this mixture for at least $20 \mathrm{~min}$ and stored in a container for at least 10 hours) and cotton wool.

All the solvents used for the analysis purchased from Merck, Germany. DDT and heptachlor standards were obtained from Sigma Chemicals, USA.

\section{Sample preparation}

All the samples were finely comminuted in a mincer; heating of the samples during comminuting is avoided by briefly chopping several times (Peter and Zeumer, 1987).
Each comminuted sample of dry fishes was divided into four parts. $1^{\text {st }}$ part was prepared as without washing (normal); $2^{\text {nd }}$ part was prepared after vigorous cold water washing (cold washing); 3 rd part was prepared after vigorous hot water washing (hot washing) and $4^{\text {th }}$ part was prepared after washing followed by 10 min boiling (boiling treatment).

\section{Extraction}

Triturate a sample of $25 \mathrm{~g}$, with sodium sulfate to dry, powdery mixture, with the aid of an extraction thimble; extract the mixture exhaustively with petroleum ether in soxhlet apparatus. Concentrate just to dryness the extract solution by a concentrator and dilute to $25 \mathrm{~mL}$ with petroleum ether saturated with dimethyl formamide (Peter and Zeumer, 1987).

\section{Clean up}

Clean up was done in two steps (Peter and Zeumer, 1987)

a) Dimethylformamide-petrolium ether partition: Transfer the solution (dissolved in $25 \mathrm{~mL}$ petroleum ether saturated with dimethyl formamide) to $250 \mathrm{~mL}$ separatory funnel. Rinse the flask with small portion of a previously measured amount of $75 \mathrm{~mL}$ dimethyl formamide. Then add the remainder of the dimethyl formamide to the separatory funnel, and shake vigorously for $1 \mathrm{~min}$. Drain the dimethyl formamide phase, and again extract the petroleum ether phase with $10 \mathrm{~mL}$ dimethyl formamide. Transfer the combined dimethyl formamide phases to a $500 \mathrm{~mL}$ separatory funnel, and add $200 \mathrm{~mL}$ sodium sulfate solution. Add a few drops of eosin solution to achieve better recognition of phase separation in the subsequent partition. Then extract successively with a $40 \mathrm{~mL}$ portion and three $25 \mathrm{~mL}$ potions of petroleum ether for 1 min each time. Wash the combined petroleum ether phases with $10 \mathrm{~mL}$ water, dry on sodium sulfate, filter through a cotton wool plug, add $5 \mathrm{~mL} n$-hexane, and concentrate to approximately $5 \mathrm{~mL}$.

b) Florisil column chromatography: About half filled a chromatographic tube with petroleum ether, and sprinkle with $30 \mathrm{~g}$ florisil in small portions through a funnel with stopcock open, tapping the column in the process. Cover the florisil with an approximately $2 \mathrm{~cm}$ layer of sodium sulphate. Drain the supernatant solvent to the top of the column packing. Pipette the sample solution on to the column. Let the solution percolate to a level of 1-2 mm above the top of the column. Then rinse the flask with small portions of eluting mixture I, add the rinsings to the column, and also let them percolate to a level of 1-2 $\mathrm{mm}$ above the top of the column. Next eluate the column with the remainder of the total $200 \mathrm{~mL}$ amount of eluting mixture I, at a flow rate of about $5 \mathrm{~mL} / \mathrm{min}$. Concentrate the eluate near to dry and add $5 \mathrm{~mL} n$-hexane to the eluate. Again 
concentrate the eluate to $1 \mathrm{~mL}$.

\section{Sample analyses}

The DDT and heptachlor residues were analyzed by GC-14B, Shimadzu with an electron capture detector (ECD), a manual sampler and GC solution software. A column of $3.1 \mathrm{~m} \times 3.2 \mathrm{~mm}$; I.D glass spiral; stationary phase silicon $\mathrm{OV}-17,5 \%$, aging $300^{\circ} \mathrm{C}$, support chromosorb-W-AW-DMCS, mesh 80/100, $1 \mu \mathrm{m}$ film thickness was used for the chromatographic separation of insecticides. The temperature was fixed for the injector at $250^{\circ} \mathrm{C}$, column at $280^{\circ} \mathrm{C}$ and detector at $280^{\circ}$ C. The carrier gas was nitrogen with a $60 \mathrm{~mL} / \mathrm{min}$ flow rate. $1.0 \mu \mathrm{L}$ sample was injected for each run and the running time was $25 \mathrm{~min}$. Standards' peak were identified by injecting high concentration of the standard ( 0.5 and $0.3 \mathrm{ppm})$ and the retention time for DDT and heptachlor were determined. Then calibration was done at 3 points $(25,50$ and $100 \mathrm{ppb})$ by composite stock standard solution. GC system was calibrated using external standard technique. Individual standard stock solution (100 mg/L) was prepared by weighing appropriate amounts of active ingredients in a brown bottle with a Teflon-lined screw cap and dissolving the weighed standard in HPLC grade hexane. Stock standard solution was used to prepare primary dilution standards. Appropriate volume of each individual stock solution was taken in a volumetric flask and mixed the solutions to obtain composite stock standard solution.

\section{Analytical quality control}

Gas chromatograph equipped with ECD was checked for linearity. Instrumental limit of detection for GCECD was $1.0 \mu \mathrm{g} / \mathrm{L}$ for organochlorine pesticides. An aliquot of dry fish samples which were collected as blank and treated exactly as a sample including exposure to all glassware, equipments, solvents and reagents used with the sample matrix. No analyte peak was detected in laboratory reagent blank. An aliquot of fortified samples matrix were prepared to which known quantities of the pesticides were added in the laboratory in $\mathrm{ppb}$ range. This laboratory fortified matrix was analyzed exactly like the sample. Extraction and clean up were done as mentioned and the recoveries from untreated control samples of dry fish fortified with the analyzed compounds at level of 25 ppb were $96-100 \%$ for heptachlor and $98-100 \%$ for DDT. Prior to injection of the first sample solution, a standard solution was injected at least three times to check the operating conditions and the constancy of the detector signals. Further linearity of the ECD signal was checked by injecting serial dilutions of DDT and heptachlor. A standard solution injected after at least every other sample solution so that any alterations of the gas chromatographic system recognized due to column contamination.

\section{Results and Discussion}

Twenty samples of five different fish species were analyzed for this purpose. All of the samples contained organochlorine insecticides are shown in Table I.

The concentrations of DDT in the samples of bombay duck at normal, cold washing, hot washing and boiling treatment were 97.0, 76.6, 49.8 and $38.195 \mathrm{ppb}$ respectively. In the samples of ribbon fish were 36.6, 30.0, 21.6 and $9.9 \mathrm{ppb}$ respectively. In the samples of shrimp at normal, cold washing, hot washing and boiling treatment were 12.6, 7.7, 6.8 and $5.1 \mathrm{ppb}$ respectively. In the samples of Chinese pomfret at normal, cold washing, hot washing and boiling treatment were 712.2, 372.1, 256.8 and $197.7 \mathrm{ppb}$ respectively. In the samples of Indian salmon at normal, cold washing, hot washing and boiling treatment were 737.2, 469.1, 142.2 and $135.5 \mathrm{ppb}$ respectively.

\begin{tabular}{|c|c|c|c|c|c|c|}
\hline \multicolumn{7}{|c|}{ Table I } \\
\hline \multicolumn{7}{|c|}{ DDT and heptachlor concentrations in the dry fish samples after various washing and boiling treatment } \\
\hline Treatment & Insecticides & $\begin{array}{l}\text { Bombay duck } \\
\text { (Loittya) }\end{array}$ & $\begin{array}{l}\text { Ribbon fish } \\
\text { (Chhuri) }\end{array}$ & $\begin{array}{l}\text { Shrimp } \\
\text { (Chingri) }\end{array}$ & $\begin{array}{l}\text { Chinese pomfret } \\
\text { (Rupchanda) }\end{array}$ & $\begin{array}{c}\text { Indian salmon } \\
\text { (Lakhua) }\end{array}$ \\
\hline \multirow[t]{2}{*}{ Normal } & Heptachlor & 1.2 & 1.2 & 44.8 & 5.3 & 4.8 \\
\hline & DDT & 97.0 & 36.6 & 12.6 & 712.2 & 737.2 \\
\hline \multirow[t]{2}{*}{ Cold washing } & Heptachlor & 0.8 & 2.0 & 29.9 & 4.2 & 4.1 \\
\hline & DDT & 76.6 & 30.0 & 7.7 & 372.1 & 469.1 \\
\hline \multirow[t]{2}{*}{ Hot washing } & Heptachlor & 0.5 & 0.9 & 26.7 & 2.8 & 2.2 \\
\hline & DDT & 49.8 & 21.6 & 6.8 & 256.8 & 142.2 \\
\hline \multirow[t]{2}{*}{ Boiling treatment } & Heptachlor & ND & 0.6 & 16.9 & 2.1 & 1.3 \\
\hline & DDT & 38.2 & 9.9 & 5.1 & 197.7 & 135.5 \\
\hline
\end{tabular}


The concentrations of heptachlor in the samples of bombay duck at normal, cold washing, hot washing and boiling treatment were 1.2, 0.8, $0.5 \mathrm{ppb}$ and not detected respectively. In the samples of ribbon fish following different treatment were 1.2, 2.0, 0.9 and 0.6 $\mathrm{ppb}$ respectively. In the samples of shrimp at normal, cold washing, hot washing and boiling treatment were $44.8,29.9,26.7$ and $16.9 \mathrm{ppb}$ respectively. In the samples of Chinese pomfret at normal, cold washing, hot washing and boiling treatment were 5.3, 4.2, 2.8 and 2.1 ppb respectively. In the samples of Indian salmon at normal, cold washing, hot washing and boiling treatment were $4.8,4.1,2.2$ and 1.3 ppb respectively.

The study on the effect of traditional washing and boiling on DDT and heptachlor in dry fish to elucidate the concentration level of dietary intake was not done before. Contamination of vegetables with pesticide residues has been reported by several researchers (Madan et al., 1996; Kumari et al., 2002, 2003) and washing was found effective in dislodging the residues as it depends on a number of factors like location of residues, age of residues, water solubility and temperature and type of washing. In earlier studies also, effects of these factors were observed in different vegetables by various researchers (Sarode and Lal, 1982a, 1982b; Dikshit et al., 1986; Geisman, 1975; Gunther et al., 1963). Some researchers reported 20-89 percent reduction of DDT in potatoes and tomatoes, fenitrothion in okra, parathion in cauliflower and malathion in okra by washing (Farrow et al., 1969; Sarode and Lal, 1982a; Elkins, 1989). Boiling was found comparatively more effective than washing in dislodging the residues in vegetables (Kumari and Singh, 2008). But the present study have been undertaken in order to provide the preliminary information on the concentration of DDT and heptachlor in dry fish after various traditional washing for the first time and to investigate their concentration level we intake actually.

From the above results it was found that all the samples of dry fishes contained DDT and heptachlor and these insecticides were not removed $100 \%$ by any type of washing, even after washing followed by $10 \mathrm{~min}$ boiling, (except in bombay duct boiling treatment sample, heptachlor was not detected). Our people think that these insecticides remain only on the surface of the dry fish and it is washed out with vigorous washing, somebody also thinks that if it is washed followed by boiling the poison will be destroyed and washed out with water. But DDT and heptachlor are nearly insoluble in water and has a good solubility in most organic solvents, fats and oils. Moreover these are highly stable molecule. In this experiment a big amount of DDT and heptachlor were washed out at various washing but a significant amount was remained due to their water insolubility, fats solubility and high stability. The concentration of DDT and heptachlor were decreased by washing due to the removal of the organochlorine insecticides present in the outer surface of the dry fish. Further decrease of organochlorine insecticide concentration in boiling treatment and hot washing treatment than cold washing treatment was due to more loss of fats and oils with hot water and organochlorine insecticides were somewhat drained out with this lost fats and oils.

\section{Conclusion}

We intake a significant amount of DDT and heptachlor with our diet when palatable dry fish is our one of the items of menu though we show our greater sincerity of washing.

\section{References}

Barua S. Escaping from organic chemical pollutants. The new nation. Internet edition. November 19, 2007. http:// nation.ittefaq.com/rss.xml

BCAS. Bangladesh Env. News Letter; No. 6, Vol. 2, Dhaka, Bangladesh. 1990. http://www.sos-arsenic.net/english/ export/1.html

Bhuiyan MNH, Bhuiyan HR, Rahim M, Ahmed K, Haque KMF, Hassan MT, Bhuiyan MNI. Screening of organochlorine insecticides (DDT and heptachlor) in dry fish available in Bangladesh. Bangladesh J Pharmacol. 2008; 3: $114-20$

Bouwman H, Sereda B, Meinhardt HM. Simultaneous presence of DDT and pyrethroid residues in human breast milk from a malaria endemic area in South Africa. Environ Pollut. 2006; 144: 902-17.

Brown AJ. Pesticide exposure linked to asthma. Sci Am. 2007; 162: 890-97.

Clapp RW, Jacobs MM, Loechler EL. Environmental and occupational causes of cancer: New evidence 2005-2007. Rev Environ Health 2008; 23: 1-37.

Dikshit AK, Handa SK, Verma S. Residues of methamidophos and effect of washing and cooking in cauliflower, cabbage and Indian colza. Indian J Agric Sci. 1986; 56: 661-66.

Elkins ER. Effect of commercial processing on pesticide residues in selected fruits and vegetables. J Assoc Anal Chem. 1989; 72: 533-35.

Farrow RP, Elkins ER, Rose WW, Lamb FC, Rall JW, Mercher WA. Canning operations that reduce insecticide level in prepared foods and in solid food wastes. Residue Rev. 1969; 29: 73-87.

Geisman JR. Reduction of pesticide residues in food crops by processing. Residue Rev. 1975; 54: 43-54.

Gunther FA, Carmen GE, Blinn RD, Barkley JH. Persistence of residues of glutathione on and in mature lemons and oranges in laboratory processed citrus pulp. Cattle Feed. 
1963; 11: 424-27.

Jones OAH, Maguire ML, Griffin JL. Environmental pollution and diabetes: A neglected association. Lancet 2008; 371: 28788 .

Kumari B, Kumar R, Madan VK, Singh R, Singh J, Kathpal TS. Magnitude of pesticidal contamination in winter vegetables from Hisar, Haryana. Environ Monit Assess. 2003; 87: 31118.

Kumari B, Madan VK, Kumar R, Kathpal TS. Monitoring of seasonal vegetables for pesticide residues. Environ Monit Assess. 2002; 74: 263-70.

Kumari B. Effects of household processing on reduction of pesticide residues in vegetables. ARPN J Agric Biol Sci. 2008; 3: 46-51.

LDWG (Lower Duwamish Waterway Group). LDW RI: Baseline HHRA attachment 4 . Toxicological profiles for chemicals of potential concern. 2007, p 39.

Madan VK, Kumari B, Singh RV, Kumar R, Kathpal TS. Monitoring of pesticide from farmgate samples of vegetables in Haryana. Pestic Res J. 1996; 8: 56-60.

Morrison RD, Newell AE. The cosolvation transport of DDT and toxaphene in xylene at a pesticide formulation facility. J Soil Contam. 1999; 8: 63-80.
Ntow WJ, Tagoe LM, Drechsel P, Kelderman P, Gijzen HJ, Nyarko E. Accumulation of persistent organochlorine contaminants in milk and serum of farmers from Ghana. Environ Res. 2008; 106: 17-26.

Peter H, Zeumer H. Manual of pesticides residue. Analysis, vol. I, working group "analysis". Germany, VCH, Pesticide Commission, 1987, pp 298-319.

Rogan WJ, Chen A. Health risks and benefits of bis(4chlorophenyl)-1,1,1-trichloroethane (DDT). Lancet 2005; 366: 763-73.

Sarode SV, Lal R. Persistence of residue of fenitrothion in or on okra. Indian J Agric Sci. 1982a; 52: 135-38.

Sarode SV, Lal R. Dissipation of fenitrothion residues on cauliflower. Indian J Agric Sci. 1982b; 52: 173-76.

Solomon G, Weiss P. Healthy milk, healthy baby. New York, Natural resources defense council, 2001. http:// www.nrdc.org/breastmilk.

UNEP. United nations environment program chemicals. Indian ocean regional report. UNEP Chemicals is a part of UNEP's technology, industry and economics division, 2002, pp 15-67.

WHO. The WHO recommended classification of pesticides by hazard. Brit J Psychiat. 2005; 187: 583-84. 